\title{
Zero Emotiveness in Business Communication SAVYTSKA Larysa
}

\author{
Simon Kuznets Kharkiv National University of Economics, Ukraine \\ E-mail address: larisa-savickaya@hotmail.com
}

Keywords: emotionality, emotiveness, emotive, zero emotiveness, business communication, business text.

\begin{abstract}
The aim of this study is to prove that the function of emotiveness in any type of business communication as a linguistic category reflects language design of communicants' emotion. The concept of zero emotiveness is considered as an example of business communication but a business text can acquire emotiveness. The semantic status of zero emotiveness in a business text has the status of potential. Zero emotiveness is manifested in words with the potential that acquire emotive connotation due to actualization of latent, probabilistic semes of emotiveness or putting semes of emotiveness from consociation to the semantic of neutral words. The degree of emotiveness depends on the status of a business text. Even in strictly standardized and regulated business texts emotiveness is presented in its zero degree.
\end{abstract}

\section{INTRODUCTION}

In linguistic theory emotions are well represented in various forms of language processing of person's emotionality. The means of emotiveness, emotives of different levels and properties are presented in detail in many linguistic studies but zero emotiveness is studied insufficiently. It seems important to examine semantics of this level of emotiveness and complete the existing classification of emotives.

\section{DEVELOPMENT OF THE CONCEPT OF ZERO EMOTIVENESS}

In the most general sense zero linguistic unit is defined in linguistic dictionary as "not materially expressed linguistic unit, a carrier of specific grammatical meaning" [1]. This interpretation applies to grammatical units.

K. Dolinin introduces the term of "zero stylistic value." He writes: "Zero stylistic value - is not lack of stylistic values, it is a potential opportunity of any word to have a stylistic meaning" [2].

In the monograph devoted to study of implicitness, the following interpretation of the term "zero" is provided.

"From structuralism point of view absence of surface expression in the system is the same sign as something that has shape (zero flexion of cases, zero ending ...)" [3].

The concept of "zero emotionality" is used in A. Filippov's article on the problem of lexical connotation. From his point of view, zero emotionality is part of the emotional meaning of the word, which, in turn, is a lexical connotation of the word. He writes: "In words analysis in isolation apart from their cover it is discovered, that intellectual value, reflecting a notion of human thought; then - the emotional value (including zero emotion), reflecting any sense of human consciousness. Both of them are potentially informative ... "[4]." The real emotional value is not perceived out of style, latter also involves a particular emotion (including zero). The listener perceives the pronounced sense not only itself, but also in terms of appropriateness of its expression, circumstances of speech and special mode of expression ... "[4].

From these citations it is evident that lexical connotation is considered as an emotional and stylistic semantic content, which includes a zero emotional meaning.

Thus, scientists agree in a common view: the concept of "zero" means the absence of any conditions, but with possible manifestation depends on various conditions.

We are going to define the concept of zero emotiveness as an example of business communication $(\mathrm{BC})$. Let's pay attention to the fact that researchers of emotions in language (Ch. 
Bally, V. G. Gak, G. Guillaume, V. I. Shahovsky etc.) are united by the idea that oral communication especially interpersonal is always emotive.

\section{MAIN ASPECTS OF ZERO EMOTIVENESS OF BUSINESS COMMUNICATION}

Any direct contact without the verbal expression of emotions of communicants reads an emotional state through body language and facial expressions. Even the silence of communicators can be eloquent and marked by intense emotions. Such communication takes place at the level of "emotional resonating without verbal language" [5]. In other words, any verbal communication between people is emotive, and therefore oral $\mathrm{BC}$ is emotive and it cannot contain zero emotiveness. Therefore, zero emotiveness is only peculiar to written forms of BC.

Let's assume that zero emotiveness of written texts in BC is their lack of emotive, but with possible manifestation of emotiveness when these texts are submerged in different communicative situations.

To confirm this statement let's refer to factual material of study. Writing texts in BC are represented by such genres as business letters (a letter to the client, a letter of recommendation, a letter of explanation, explanatory note, sales letter, and so on), business correspondence (correspondence between business partners), documentation (contracts, agreements, orders, etc.).

Each of these genres differs by stylistic features, degree of formality and regulation. It is not possible to collect them into a single group to determine zero emotiveness in them. Let's consider each of these genres individually.

Group of Business letters Business letters are characterized by a low degree of formality and they are less restricted by the set of stylistic features. It allows the authors to use one or another emotive. Here is an example - extract from a letter to client (for ethical reasons, proper names are not mentioned).

Cooperating with XXX, you will get excellent service, competitive prices and high quality products! We will be glad to consider your offers on cooperation! For our clients we offer the following services:

- free delivery of products and services in Kharkiv and Kharkiv region. Delivery to other regions is performed by rail and automobile transport to the address specified by customer.

- Every customer is assigned by personal manager, who provides excellent service.

In the letter text mentioned above emotives are expressed by adjectives and adverbs: excellent service, competitive prices and high quality products. To attract customers' attention and highlight benefits from cooperation the author uses the exclamation mark.

Group of Business Correspondence Business Correspondence text cannot have zero emotiveness because they are always emotively marked. Any correspondence including texts on BC is a written fixation of a dialogue. This contains language emotional design of participants in this dialogue. Emotives of different levels is presented in text on BC in Ukrainian as well in English. For example: We apologize for delay. You will be contacted by sales manager to resolve this situation and not to hurt your interests.

Group of Documentation This definition we use for only those documents which are characterized by certain standards in design and a high degree of formality. They include orders, contracts, agreements, and resolutions and so on. This type of documents is the most interesting in terms of emotive functioning. Let's consider an extract from a contract.

1. Prices under the Contract and order of payment

1.1. Price of the Contract is $\$ 25500820$ (twenty-five million five hundred thousand eight hundred and twenty USD).

1.2. Price of the Contract includes the price of goods, freight charges, VAT and other taxes and customs duties paid or payable; insurance, loading / unloading, preparation of premises, installation, commissioning and other possible costs of a participant reimbursed according to the Contract.

1.3. Price of the Contract is fixed and cannot be changed during the Contract execution. 
14. Customer within 10 banking days on basis of invoice issued by Supplier makes an advance payment of $30 \%$ of the price of the Contract.

15. Customer pays Supplier for goods and related services in accordance with the schedule (Appendix 2 to the Contract) within 10 banking days after submission of the bill of lading and the invoice.

16. Advance payment is calculated in final payment.

1.7. Final settlements are made after actual execution of the Contract within 10 banking days from the date of delivery. Bills are issued on the basis of the Act of transportation and acceptance and commissioning, signed by both sides and submitted by shipping documents.

In the extract from the text mentioned above there aren't any emotions (affective, connotative) according to V. I. Shakhnovsky typology of emotions.

From a traditional point of view, it is neutral and non-emotive. However, it is not possible to say that it is deprived of emotion in its language design. This text was made by a person, a businessman who is interested in benefits, and thus he experienced certain feelings and emotions. Getting into the situation of discussion, the Contract can cause a variety of feelings and provide emotions in communicating: doubt, surprise, resentment, anger or satisfaction, joy. This emotive function may belong to any word in the Contract: terms of delivery, the price of Contract, payment methods and so on. As I. A. Sternin writes "In many cases, a language unit is systematically unemotional, but its potential emotionality exits verbally or contextually. Speaker's emotionality can be found in implementation of any word" [6].

According to the basic principal of study of emotiveness every word, every sentence has emotiveness. This idea is originated in psycholinguistics.

E. Yu. Myagkova after V. N. Gridin proves that any word has its emotional loading, emotional component is found not only in the meaning of words, which are traditionally considered as emotional, but also in neutral in terms of lexeme emotionality.

A.V. Kintsel supports this idea saying that: "... any lexeme can be representative of a certain emotion in a particular text" [7]. Developing this statement, the scientist concludes that a text, traditionally recognized as neutral, has a minimal degree of a positive emotion. "The units of language considered as neutral, often represent dominant emotions of positive modality with low intensity" [7].

This idea is close to our statement that any Business Text which is traditionally recognized as emotionally neutral (e.g., contract, agreement) has an emotive component. Emotiveness is manifested in zero degree because a stylistic limitation of these texts does not allow to use other forms of emotiveness (explicit and implicit). In this case, it is reasonable to talk about zeroemotiveness.

Analysis of factual material allows to determine zero emotiveness as potential ability of a business text, which has been traditionally recognized as emotionally neutral, becoming emotionally dependent on the nature of a communicative situation.

When characterizing zero emotiveness it is necessary to disclose semantic status of the concept. Let's turn to classification of emotions by V. I. Shakhovsky again [5]. This typology has been developed to study texts of fiction. Extrapolation of using in art communication research methods of emotiveness to study the features of emotiveness in BC allows to drawing the following conclusion: the semantic status of zero emotiveness has a status of potential. Zero emotiveness is manifested in words with potential e.g. in words that acquire emotive connotation due to actualization of latent, probabilistic semes of emotiveness or putting semes of emotiveness from consociation to the semantic of neutral words [5].

Analyzing texts of agreements, contracts and agreements it was established that these words with potential are numerals expressing such objects as prices of Contract, payments, debts, penalties, salaries, working conditions and so on.

Let's analyze an extract from the Contract.

3.1. "SELLER" undertakes to transfer equipment within 10 working days from the date of $100 \%$ payment. The date of transfer is the date of signing the consignment. 
3.2. "BUYER" undertakes to pay directly to "SELLER'S" account:

3.2.1. The amount of 458.000 UAN till to 10.12.2016.

3.3. To pay for equipment "BUYER" in payment orders in the column "purpose of payment" indicates the number and date of the paid bill and the Contract.

3.4. The obligation of "BUYER" as for payment is considered to be fulfilled from the moment when funds are debited "SELLER'S" account (payment date). "BUYER" must inform "SELLER" by fax about the payment during working day the payment is made by sending a copy of the payment order.

This text does not contain emotive words, traditionally it is considered neutral. However, lexemes with the logical-rational semantic: within 10 working days, the amount of 458.000 UAN, till to 10.12.2016, put emotive semes in a particular communicative situation. Emotive settlement of semes is performed by the partners of communication: for the buyer mentioned the amount or date can cause disagreement and dissatisfaction, while the seller is satisfied with such conditions. Moreover, as business practice shows, these neutral-rational words may have emotionally powerful energy.

Emotive potential of semantic of neutral words is explained that an object causes some interest by the fact, and thus non-essential features of the concept can become significant and get emotional understanding. Accordingly, neutral words are becoming emotively affective.

\section{CONCLUSIONS}

Revealing the nature of zero emotiveness, it should be noted that "zero" concept is nominal, because "even if there aren't any rational signs of verbal interaction between partners a hidden emotional dialogue is always obvious" [5]. In case when emotion was born in depths of human psyche and not found in the form of linguistic expression in a communicational situation, we can talk about zero degree of emotiveness.

Thus, any text, including business, is a product of a human activity. It has emotiveness. The degree of emotiveness depends on the status of the text. Even in strictly standardized and regulated business texts emotiveness is presented in its zero degree.

\section{References}

[1] V. D. Starichenok, Large linguistic dictionary, Rostov-on-Don, 2008, p. 356.

[2] K. A. Dolinin, French Stylistics, M., 1987, p. 96.

[3] Implicit in language and speech, E. G. Borisov, Yu. S. Martem'yanov, M., 1999, p. 16.

[4] A. V. Filippov, On the problem of lexical connotation, in: Problems of linguistics, 1978, № 1, p. 57.

[5] V. I. Shahovsky, Linguistic theory of emotions, M., 2008, p. 77.

[6] I. A. Sternin, Structural semasiology, evaluation and emotion, in: Language and emotions: nominative and communicative aspects: collection of scientific papers, Volgograd, 2009, p. 48.

[7] A.V. Kintsel, Psycholinguistic study of emotionally-semantic dominant as text-forming factor, Barnaul, 2000, p.p. 38-39. 